\title{
REVIEW OF THE EFFECTIVENESS OF INFORMATION AND COMMUNICATION TECHNOLOGY (ICTS) IN THE TREATMENT OF TYPE 1 AND TYPE 2 DIABETES
}

\author{
Parnian Asgari1 ${ }^{(D)}$, Elham Nazari2*(D) \\ ${ }^{1}$ MSc Student, Department of Medical Records and Health Information Technology, Faculty of Paramedical Sciences, Mashhad University of \\ Medical Sciences, Mashhad, Iran. \\ ${ }^{2}$ PhD Student of Medical Informatics, Mashhad University of Medical Sciences, Mashhad, Iran.
}

\begin{tabular}{|c|c|}
\hline Article Info & A B S T R A C T \\
\hline Article type: & \multirow{6}{*}{$\begin{array}{l}\text { Introduction: } \\
\text { In the field of health, information and communication technology plays an } \\
\text { important role, the world is experiencing the era of communication, the } \\
\text { field of health is not asymmetrical. According to the study, Iran is one of the } \\
\text { countries that is at high risk of diabetes, and continues to increase in Iran } \\
\text { and in most countries. The purpose of this paper is to review the literature } \\
\text { on the effectiveness of Information and Communication Technology (ICTs) }\end{array}$} \\
\hline Review & \\
\hline Article History: & \\
\hline $\begin{array}{l}\text { Received: 2019-03-08 } \\
\text { Revised: 2019-04-28 }\end{array}$ & \\
\hline $\begin{array}{l}\text { Revised: 2019-04-28 } \\
\text { Accepted: 2019-05-17 }\end{array}$ & \\
\hline & \\
\hline
\end{tabular}

\section{Elham Nazari}

PhD student of medical informatics,

Mashhad University of Medical

Sciences, Mashhad, Iran.

Email: nazarie951@mums.ac.ir

\section{Material and Methods:}

This study was conducted as a review and through a search of valid information databases such as PubMed, Science direct, and Google Scholar. After the final extraction from the 106 papers in the cellular field $37 \%$ and $36 \%$ in telemedicine and $27 \%$ in the Internet topic from 2010 to 2018, were finalized.

\begin{abstract}
Results:
The findings of the study showed that the recent developments in information technology combined with services for cost optimization have increased and the current use of information technology (IT) offers unique opportunities for patients with diabetes. Internet, mobile phone and telemedicine services can facilitate and improve communication between patients and healthcare professionals and play an important role in managing diabetes. The growing challenge is the proper management of diabetes to play an important role by employing innovative approaches aimed at improving patient outcomes and reducing the incidence of adverse healthcare systems.
\end{abstract}

\section{Conclusion:}

This study is an overview of information and communication technology research in diabetes management and can help researchers measure the effectiveness of information and communication technology in diabetes self-care and therapeutic systems in different areas and motivate selfmanagement. Cost reduction, technology acceptance and satisfaction.

Keywords:

Telemedicine, Diabetes Mellitus, Information Technology, Self-Management, Mobile Health Intervention, Internet Intervention, E-health.

How to cite this paper

Asgari P, Nazari E. Review of the Effectiveness of Information and Communication Technology (ICTs) in the Treatment of Type 1 and Type 2 Diabetes. Front Health Inform. 2019; 8(1): e12. DOI: 10.30699/fhi.v8i1.182

\section{INTRODUCTION}

Chronic diseases are the leading cause of death in the world, accounting for $60 \%$ of total mortality [1] . Diabetes is one of the major public health issues in the world. The increase in diabetes-related health outcomes has estimated that 285 million people without diabetes have been affected by diabetes and the cost of universal health care services was $\$ 376$ billion in early 2010, with a population of 439 million and $\$ 490$ billion the cost of 2030 will increase. According to national diabetes studies, in 
the 2005-2008 periods, 79 million Americans from the US population aged 20 years and older $(35 \%$ of the population aged 20 years and older) were diabetic. About 30.3 million different people or $9.4 \%$ of the US population had diabetes in 2015 [2]. In the United States, direct medical and medical costs have risen to 116 billion and $\$ 58$ billion in 2007 [2].

One of the challenging challenges of the 21st century is the widespread spread of the disease in developing countries. Nearly 390 million people around the world have diabetes mellitus by 2015 , and it is estimated that the number of people infected will reach 592 million by 2035 [ $\underline{3}, \underline{4}]$.

According to experts from the World Health Organization (WHO), the prevalence of Type 2 diabetes in Iran by the year 2025 is expected to be around 5215000, and this figure will reach 6.4 million in $2030[\underline{4}, \underline{5}]$. According to estimates from the Ministry of Health, about $\$ 1.1$ billion of the total budget of the ministry has been used to treat $2205,000$ diabetic patients in the country [ 6,7$]$.

The world is experiencing the era of communication; health is also not an issue. Therefore, the field of information and communication technology (ICTs) has a prominent role. In the field of health, information and communication technology (ICTs) is gradually playing an important role, the presence of information technology nowadays, it is very important to consider clinical, managerial, and decision-making support from specialists and managers [్].

Given the prevalence of diabetes in the world, the use of new methods in biomedical research has been very much considered. Knowledge-based information technology (IT) is one of the ways in which it can discover new and innovative connections and affiliations that are useful to physicians. Extracting knowledge from a large amount of data related to medical records by using computer knowledge and information technology leads to identifying the causes of disease, prediction and treatment of diseases, and can provide useful information about the diseases and the environmental factors that govern it to health professionals $[\underline{7}, \underline{8}]$.

Therefore, identification and diagnosis of diabetes patients is very important for policies, public health and clinical practice [9]. Health information technology (HIT) offers an opportunity to increase adherence to medications through electronic reminder systems. The term "HIT" Healthcare professionals point out electronic systems that can be used to store, share and analyze health information. The use of HIT creates a special help for patients who are unwittingly involved with the disease, such as unknowing persons Disabled and illtreated, such as those with a history of amnesia [10].
Access to mobile technology has grown rapidly over the past two decades and is increasingly being used in healthcare for various purposes [11].

Self-care is a process that the patient should control of the disease every day. Proper diet after drug treatment, blood glucose control, level of activity and care from the feet are the most important activities for the care of diabetics who can be effective in evaluating cases in hospitals and effective healing [12]. Examples include reminders Audio, Featured Apps ("MOBILE APP"), Short messages, Messages or Messages the information sent automatically to the patient's mobile phone is accessible as text messages on any mobile model

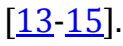

Therefore, it is necessary that an assessment be made to determine the effects of HIT on promoting and adopting the drug in diabetic patients. Type 2 and 1, which includes a detailed analysis based on scientific evidence. However, further research is needed in this area, and it is also necessary to understand the reason for not joining new technologies and changing user behavior. Failure to adhere to continuous and accurate drug use is an important health phenomenon and has a major impact on treatment, especially in primary care, which affects a large number of patients, especially the elderly $[\underline{16}, \underline{17}]$.

Among the useful tools is the use of CGM for the sustainability of blood glucose known as CGMS, or a glucose monitoring system in Iran and its strength in glucose-cloning in scientific areas [18]. Therefore, due to the need to pay attention to diabetes, the disease is known as a costly and problematic chronic illness both to the patient and to health care system. Considering the necessity of using the technologies and information technology in the world today in the field of medicine, this study aims to prepare a review article on the impact of ICTs on type 1 and type 2 diabetes.

\section{MATERIALS AND METHODS}

This research was conducted as a review and through search of reliable databases from PubMed, Science Direct, and Google Scholar. The search strategy was applied as follows:

\section{Search strategy}

"information technology" AND "diabetes mellitus" AND full text[sb] AND ("2010/01/01"[PDat]: "2018/12/31"[PDat])

"information technology" AND "diabetes mellitus" AND full text[sb] AND ("2010/01/01"[PDat]: "2018/12/31"[PDat] ) AND Humans[Mesh]

"information technology self-management" AND "diabetes mellitus" AND full text[sb] AND 
("2010/01/01"[PDat]: "2018/12/31"[PDat]) AND Humans[Mesh]

"mobile health intervention" AND "diabetes mellitus" AND full text[sb] AND ("2010/01/01"[PDat]: "2018/12/31"[PDat]) AND Humans[Mesh]

"Telemedicine" AND "diabetes mellitus" AND full text[sb] AND ("2010/01/01"[PDat]: "2018/12/31"[PDat]) AND Humans[Mesh]

"internet intervention" AND "diabetes mellitus" AND full text[sb] AND ("2010/01/01"[PDat]: "2018/12/31"[PDat]) AND Humans[Mesh]

"ehealth" AND "diabetes mellitus" AND full text[sb] AND ("2010/01/01"[PDat]: "2018/12/31"[PDat] ) AND Humans[Mesh]

The criteria for accepting the articles in question were that English articles for human beings were selected in full text in the time period from 2010 to 2018. After removing duplicate and unrelated, about 106 articles in terms of title, abstract and full text with the aim of the impact of information and communication technology Patients were evaluated (Fig 1).

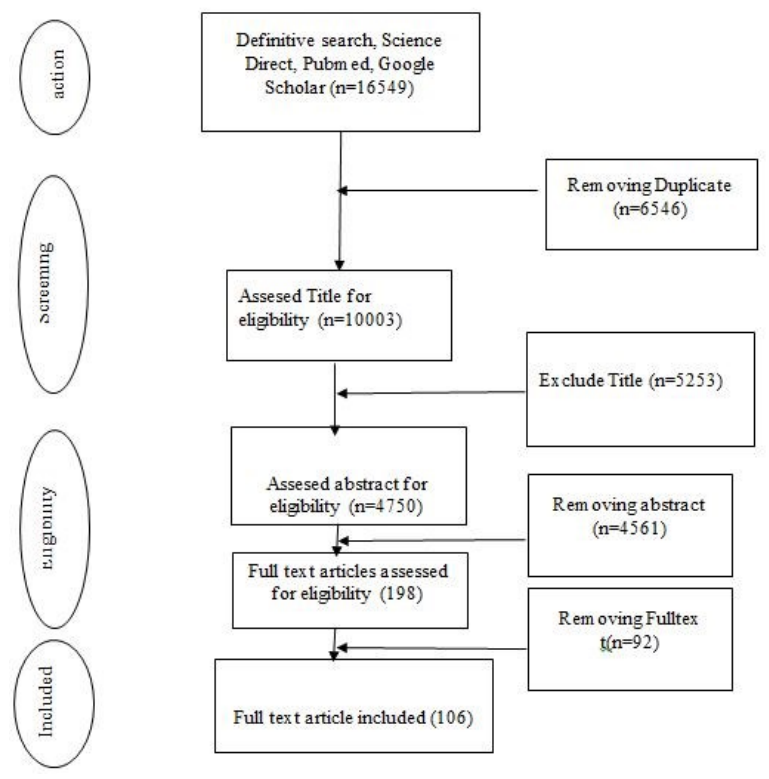

Fig 1: Summary of the research process

\section{RESULTS}

In general, by examining all interventions in the field of information technology in diabetes, we categorize all interventions in 3 categories of interventions: 1) mobile, 2) telemedicine and tele-monitoring, and 3) Internet.

\section{Mobile phone}

In parallel, cellular networks and portable devices have a significant impact on society, given their pervasiveness and the high presence and penetration of the global market. Mobile messaging for meeting reminders, medication reminders to monitor chronic conditions, and providing psychological support are also used not only in developed countries but also in developing countries [19].

Mobile phones are increasingly available worldwide. Have access and have a growing impact on society. In 2013, around 6.8 billion mobile subscribers worldwide were used (world population: 7.1 billion) [20]. Additionally, research on m-Health or HIT often involves direct end-users, several published studies on the availability of diabetes technology among participants with a variety of technological skills, or income and education $[\underline{21}, \underline{22}]$.

In the Zhangx et al study, they were able to absorb enough patients in the first year after the diagnosis, thus extending the criteria for inclusion to include diabetes patients who had been referred for more than a year before enrollment Thus, the study found a new number of diabetic patients and most participants were exposed to diabetic drugs or just a drug and yet found no relationship between the duration of illness and the duration of membership in diabetes mobile study studies. However, overall positive results have been reported [23].

In a study by Majid A. Al-Taee et al. an Internet of things (IoT) support self-management of diabetes. Such protections include self-management of diabetes, clinical interaction in time, and patient feedback, taking into account patient needs, using patient data and disease history. The platform understands to what extent the patient's activities are done correctly in accordance with their individual treatment plans, showing indicators of health based on rules and guidelines, and creating appropriate warnings and feedback from the user's side. The Internet of things (IoT) is a prototype of a fully functional system designed and implemented to manage diabetes, and at the end when it's completed, success has shown a high level of patient acceptance [24].

In the Goh et al study, 84 patients with type 2 diabetes were screened from a primary care clinic for diabetes. The program record showed that weekly use of the program for more than 8 weeks was monitored from any nutrition or exercise in that week. Data on demographics, diet and exercise motivation, diabetes self-efficacy (diabetes capability scale), and clinical variables such as body mass index, blood pressure and hemoglobin glycosylated were collected. Three mobile-based applications reported the following rates: at least users (66 of 84 patients, $78.6 \%$, without a program, or just in the first 2 weeks), common users (decreasing) Ten of 84 patients, $11.9 \%$, were used weekly for the first 4 weeks), and permanent users 
( 8 out of 84 patients, $9.5 \%$, weekly for all 8 weeks or more than 8 weeks). Uses in Users were significantly higher in women than the proportion of odds attributed to a user who frequently used the program, which decreased or did not use after the 4th week. A lower-than-program user is also significantly higher and people get higher motivational scores at the beginning of the exercise. This overall study provides an overview of the use of a calorie monitoring program among patients with type 2 diabetes and management in primary care [25].

The Diabetes Application Technology Program first aims to register patients with diabetes recently and their disease has been diagnosed so that patients are in the first year of the disease after diagnosis of diabetes. Because it seems that patients whose newly diagnosed illnesses benefit more from the mobile app for type 2 diabetes, as they will probably be better off learning new diets and changing lifestyles. In addition, the important point is that to a small extent, it has been working on the motivational part of mobile apps for a patient with diabetes $[\underline{25}, \underline{26}]$.
Syarafina Izahar et al., Found that searching for diabetes programs in the Apple Apps Store and Google Play found 100 and 246 diabetes programs, respectively. Only 35 (15.9\%) of the mobile medical apps were found: $16(16 \%)$ of the Apple store and $19(7.72 \%)$ of Google Play found. Their features are shown in Fig 2.

Of the included apps, 87.5 percent of Apple Store apps and all Android apps from Google Play were less than $50 \mathrm{MB}$ in size. A fairly large amount of Android apps (73.7-84.2\%) can be downloaded for free, and can also be used offline and will use data compared to Apple's store plans (68.7-75\%). On the other hand, a large part of the iOS apps (56.3\%) had a more remarkable feature than the store apps (Google Play, 36.8\%). The features of the smallest apps used by the iOS, iPad app to learn about diabetes (12.5\%), automatic data entry (18.75\%) and counseling (18.75\%). In total, three apps from the Apple Store have provided counseling as one particular The self-provided, while none of Google Android apps have the potential to [글 (Fig 2).

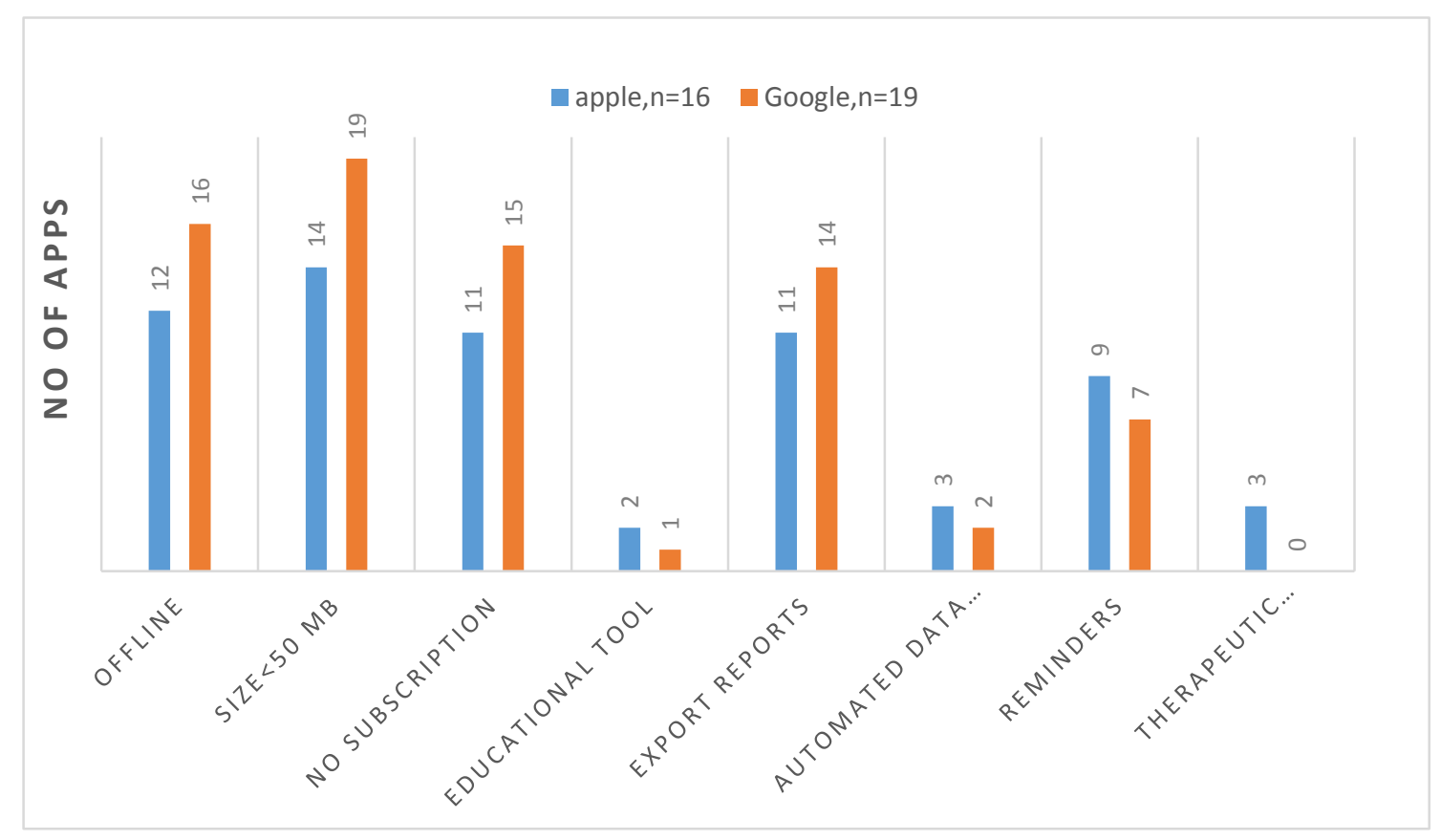

Fig 2: Features of mobile apps on Apple iPhone and Google Android

The widespread finding and support and support section are the most common features of US diabetes programs [28, 29]. However, a small number of programs containing more than 12 cases show that some programs can provide a comprehensive set of tools for controlling diabetes [30]. Psychosocial support, disease-related warnings/reminders, and information on BP, cholesterol and body mass index are highlighted in only a small percentage of the programs, suggesting that there are many opportunities for developing diabetes mobile apps. $[\underline{28}, \underline{31}]$.

It will show that the information available in patient trials, health care providers and psychological support is important for patients [리]. Information on the support sector, for example, psychological support to patients' health greatly affects [푸, $\underline{33}$, 34], psychological interventions can improve the 
patient's individual abstinence Help them [으, $\underline{35}$, 36]. Failure to provide information on the psychological aspects of self-care in people with diabetes is a missed opportunity that should be taken into consideration. Most programs do not provide information on health care providers or facilities, so these programs cannot facilitate and improve decisions on treatment resources [ㅌ6]. In addition, mobile apps are recommended as complementary to standard treatments for the prevention of chronic disease and health promotion [37].

The development of a unit based on self-care and patient care services [38]. It requires is that patients actively participate in their care and decision making and provide health care providers based on the patient's individual needs and preferences [요. While the results are generally positive, the rates of technology use vary significantly, with some of them varying from $13 \%$ to $92 \%$ [ $\underline{39}, \underline{40}]$.

Somewhat different because of different design studies and Types of devices that make it difficult to compare results and make definitions. All patterns of use in this area are difficult due to its widespread use, since applications vary widely between individuals and over time, and in this regard modeling methods Such as latent class growth modeling (LCGM), has a lot of value in identifying, isolating, and unpredictable behavioral paths. Since most programs Mobile-based services do not provide many of the features and types of information that is essential for self-governance, and in some studies it has recommended for future mobile applications diabetes research and therapeutic exercises $[\underline{41}, \underline{42}]$. Table 1 shows some of the health problems and needs of mobile healthcare and m-health solutions.

\section{Telemedicine}

The study by Jeong JY et al. Was designed to determine the effectiveness of the telemedicinebased telemedicine (telemedicine) tele-monitoring glucose control service and tele-monitoring (remote monitoring) as compared with conventional therapy in type 2 diabetes patients. In this 24-week randomized controlled clinical trial, 338 patients with type 2 diabetes in four South Korean hospitals were randomly assigned to a control group (group A, 113), a telecontrol group (group $B, 113$ ) $n=$ or a telemedicine group (group $\mathrm{C}=\mathrm{n} 112$ ). The decrease in HbA1c concentration after 24 weeks was observed in conventional groups, telemedicine and telemedicine. Fasting glucose concentration in the trap monitoring groups (caregivers Telemedicine was lower than the conventional group. Hypoglycemia rates in the telemedicine group were lower than the other two groups, and the observance of medications in the telemonitoring (tele-care) and Telemedicine were better than the usual ones. No serious incident related to telemedicine was reported. All people underwent diabetes care education, including information on blood glucose monitoring (SMBG), dietary recommendations and physical activity recommendations recommended by the American Diabetes Association. The initial result was a change in HbA1c concentrations from the beginning to 24 weeks, secondary results include changes in fasting blood glucose (FBG), lipid, body weight and Body mass index (BMI) and regular observation of drugs and safety outcomes, including the number of hospitalization and the number of emergency rooms due to complications of diabetes. Side effects; and laboratory results, including serum concentrations of aspartate aminotransferase (AST), alanine aminotransferase (ALT), and creatinine. Finally, telemedicine was highly effective in improving access to health care and clinical outcomes for managing diabetes [녀].

Table 1: Problems and needs of mobile health technology and $\mathrm{m}$-health solutions

\begin{tabular}{|c|c|c|c|}
\hline $\begin{array}{l}\text { ICT } \\
\text { interventions } \\
\text { in diabetes }\end{array}$ & $\begin{array}{l}\text { Problems } \\
\text { and } \\
\text { requirements }\end{array}$ & $\begin{array}{l}\text { The } \\
\text { mentioned } \\
\text { solutions }\end{array}$ & References \\
\hline \multirow[t]{3}{*}{ m-health } & $\begin{array}{l}\text { The high cost } \\
\text { of the mobile } \\
\text { phone }\end{array}$ & $\begin{array}{l}\text { The low } \\
\text { cost of } \\
\text { Android } \\
\text { mobile } \\
\text { devices is } \\
\text { relative to } \\
\text { iOS devices } \\
\text { in terms of } \\
\text { price and } \\
\text { technology }\end{array}$ & $\underline{19}-\underline{27}$ \\
\hline & $\begin{array}{l}\text { security } \\
\text { problems }\end{array}$ & $\begin{array}{l}\text { Train } \\
\text { security } \\
\text { systems to } \\
\text { share } \\
\text { medical } \\
\text { information } \\
\text { through the } \\
\text { app }\end{array}$ & $\underline{42}-30, \underline{32}-$ \\
\hline & $\begin{array}{l}\text { Internet } \\
\text { connection }\end{array}$ & $\begin{array}{l}\text { Public and } \\
\text { private } \\
\text { support for } \\
\text { expanding } \\
\text { the mobile } \\
\text { and } \\
\text { wireless } \\
\text { network to } \\
\text { the remote }\end{array}$ & $\underline{19}-\underline{42}$ \\
\hline
\end{tabular}

Another study showed that distant care programs in people with diabetes had no side effects. However, the implementation of diabetic retinopathy monitoring programs can improve the overall assessment of diabetic patients $[\underline{44}, \underline{45}]$. In a study on diabetes patients that included registers, imaging, 
grading and tracking/reporting, results showed that $76 \%$ of these patients could consult with a physician remotely and $8 \%$ of patients were tested only directly and $16 \%$ were tested again [46]. The telemedicine screening program and its workflow process can directly reduce the challenges of providing screening services and can be used to diagnose patients with diabetic retinopathy [47].

In Guttmann-Bauman et al. the effect of treatment sessions as a video conferencing on the results of care for children with type 1 diabetes in the rural area. Patient Satisfaction Questionnaire was also performed from 27 patients who participated in the first year of the program. Patients showed a great deal of satisfaction with the service, and compared the majority of video conferencing sessions with online visits. The visits of healthcare physicians and carers at video conferences are necessary in diabetic patients, especially those who live in remote areas of specialized centers [요].

In a study conducted by Tuula Karhula et al. For a total of 250 patients with diabetes mellitus monitoring and mobile monitoring, each patient in each group has a remote monitoring intervention package for testing. And the package included a mobile phone with a specific application, a personal mobile health record (PHR), and a set of measurement devices attached to the patient's PHR account. The PHR mobile app was needed for manual or automatic reporting. All patients had blood pressure that could be connected to a mobile phone via Bluetooth. When patients measured their blood pressure, the amount was automatically transferred to the PHR using a binary short message text message (SMS). Other health parameters must be taken into consideration include: body weight, blood glucose levels for diabetic patients to measure and send these values manually via phone to PHR once a week. The intervention was carried out by a remote monitoring system in Finland (Fig 3). Selfcare server is the central part of its architecture. Providing services for storing and accessing remote patient monitoring RPM related to the process of self-management RPM data included various types of information: Health parameters recorded by relevant measurement devices, a personal care plan by health care providers agreed with the patient and data from the EHR [49]. The architecture is shown in Fig 3.

\section{Patient}

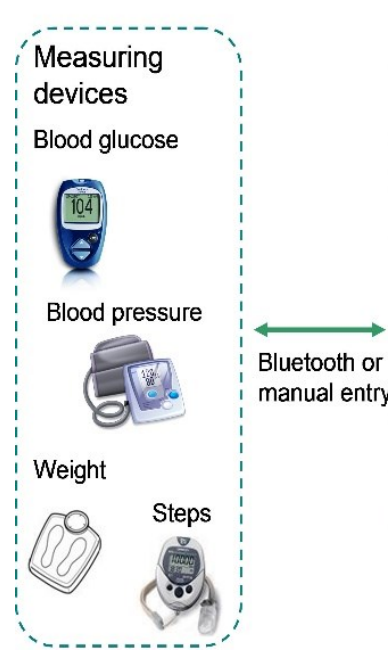

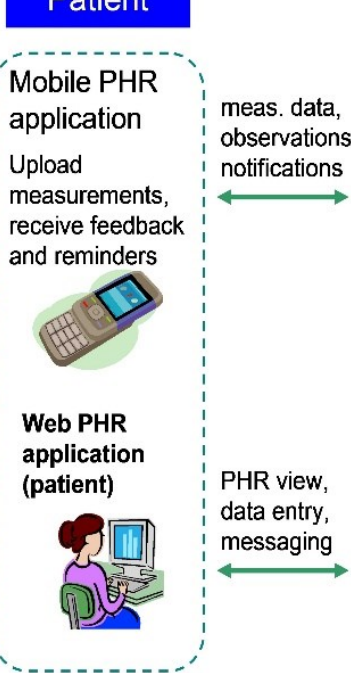

\section{Health professional}

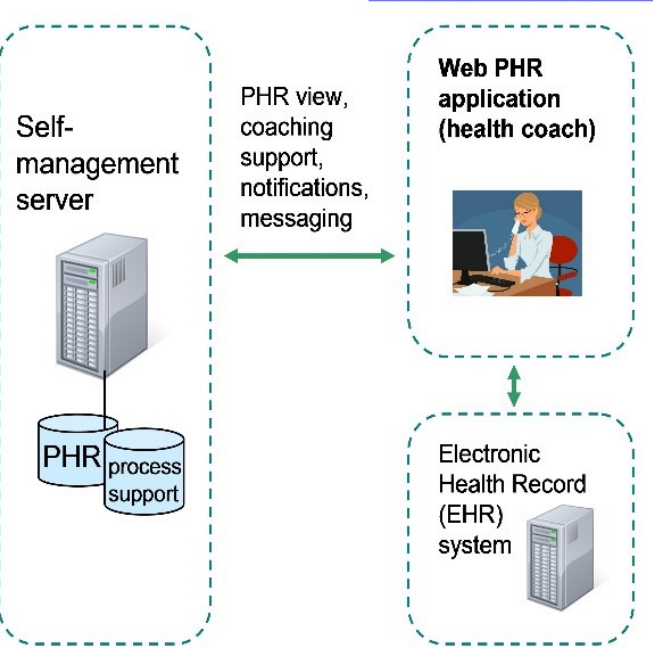

Fig 3: Technical support for the health monitoring system of the patient with distant distances

In the study of Tuula Karhula et al., The outcomes of the study were the lack of recognition of patients from mobile phones. $88 \%$ of diabetic patients were familiar with mobile phones. The intervention showed that the current performance of patients does not affect their health quality. Diabetic patients: beta $=0.875(\mathrm{P}=0.85)$ for the physical score and beta $=-0.770(\mathrm{P}=0.52)$ for the subjective score. There was no significant difference in the measured parameters in the type 2 diabetes and only in the waist circumference of the diabetic patient was an intervention (beta=-1.711, $\mathrm{P}=0.01$ ) and a significant difference was reported [49].

In studies conducted on diabetic patients, telemedicine screening was found to be a valid screening method, and most people wanted to use this method in subsequent experiments [ $\underline{50}-\underline{52}]$. Studies in remote surveillance centers have shown that a remote medical screening program is a safe and efficient device for the diagnosis and treatment of diabetic retinopathy. Data suggest that diabetic diagnostic retinopathy screening program can be 
prevented to prevent blindness in diabetic patients, and the integration of telemedicine and screening is a collaborative effort between primary care physicians and ophthalmologists in timely and effective screening and treatment $[\underline{50}, \underline{53}]$.

In the study of Yan and Taiwan health insurance partners, a pharmaceutical drug exchange platform introduced the Pharma Cloud program in 2013. The aim of this study was to investigate the effects of the registration of drugs registered in drugs that were used extensively and in patients with diabetes. Patients who performed the drug registration rate of more than $25 \%$ were classified as the upper and lower group as the downstream research group and the dependent variables, the probability of receiving medications and the days of drug and the overlap of the subjects studied remotely Checked in.

A total of 106508 patients with diabetes were randomly selected. As a result, the system of sharing drug registration has led to the fairness of drug mediation among diabetic patients. However, the use of more than $25 \%$ did not reduce the number of unused drugs. The overall effect may be due to an increase in internal control through the system's warning system in hospitals and the examination of doctors from cases [누] .

In several studies, the results showed that all socioeconomic costs of the medication-based diabetic retinopathy screening model were significantly lower than the physician-based model cost of $\$ 173$ per person. In general, in many parts of the world, there is a strong logic for telemedicine implementation based on economic, social and cultural aspects [ $\underline{55}-\underline{57}]$. Another study showed that remote doctor ophthalmologist examination of diabetes retinopathy was very cost effective compared to direct screening by specialists [묘].

If screening is done every two years, its cost is very profitable, but its non-occurrence will lead to higher costs (58-60\%), also showed that intervention for participants who resist and fail to intervene They are due to unknowns whose barriers are based on changing people's beliefs. These findings can lead to natural changes in a population that, even in positive experiments with motivational interviewing, one percent of respondents do not respond to this approach [도-63], and the motivational interview succeeds in changing behavior in a short period the term was for participants who needed real feedback on their behavioral behavior [64]

In a study by Jun Yang Lee et al., Telemedicine has been used globally to manage diabetes because of its potential for improving access to health care and clinical outcomes. Few studies have spoken of telemedicine economic benefits that may help inadequate capital in potentially important plans. The goal of the author is to systematically evaluate the economic evaluation of telemedicine medicine in diabetes care, assess the quality and summarize evidence of cost-effectiveness in diabetes. Then assesses the quality of the study in terms of measuring effectiveness, cost measurement, economic model, as well as the horizons. The costs of healthcare providers are the main predictor of the overall cost. In particular, the use of telemedicine was a useful and cost-effective screening for managing diabetes, similarly, the use of telephone and telephone reminders in managing diabetes was effective. Among the therapist's strategies, the most cost-effective interventions were. Future research to provide evidence of long-term experience Telemedicine and facilitate allocation of resources [65]. See Table 2 for telemedicine problems and solutions.

Table 2: Telemedicine problems and requirements

\begin{tabular}{|c|c|c|c|}
\hline 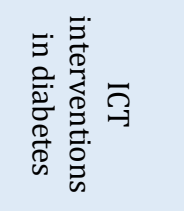 & 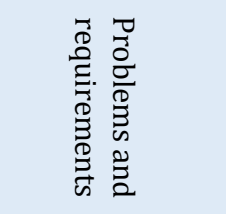 & 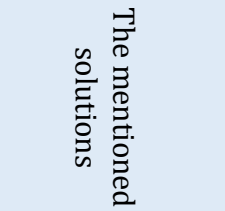 & 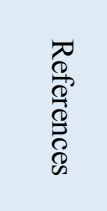 \\
\hline \multirow[t]{4}{*}{ Telemedicine } & $\begin{array}{l}\text { Costs of } \\
\text { Telemedicine }\end{array}$ & $\begin{array}{l}\text { Adequate } \\
\text { funding from } \\
\text { private and } \\
\text { public sectors }\end{array}$ & $\frac{43}{\underline{53}}-\underline{-48}$, \\
\hline & $\begin{array}{l}\text { Information } \\
\text { management } \\
\text { and equipment } \\
\text { implementation }\end{array}$ & $\begin{array}{l}\text { Management } \\
\text { and monitoring } \\
\text { in the form of } \\
\text { continuous } \\
\text { subscription } \\
\text { and reporting, } \\
\text { and the } \\
\text { implementation } \\
\text { of equipment } \\
\text { and subsequent } \\
\text { inspection of } \\
\text { equipment and } \\
\text { efficient } \\
\text { observers in } \\
\text { the creation } \\
\text { and } \\
\text { development of } \\
\text { a free Wi-Fi } \\
\text { network or at a } \\
\text { very low cost in } \\
\text { all remote } \\
\text { areas }\end{array}$ & $\begin{array}{l}\frac{51}{53}-\frac{56}{58}, \\
\frac{58}{63}-65\end{array}$ \\
\hline & $\begin{array}{l}\text { Technical } \\
\text { training by } \\
\text { specialist }\end{array}$ & $\begin{array}{l}\text { Computer and } \\
\text { Internet skills }\end{array}$ & $\begin{array}{l}\frac{43}{48}-\frac{45}{49}, \\
\frac{51}{58}, \underline{\frac{52}{62}}, \\
\underline{65}\end{array}$ \\
\hline & $\begin{array}{l}\text { Information } \\
\text { support }\end{array}$ & & $\underline{67}-\underline{57}$ \\
\hline
\end{tabular}




\section{Internet}

In the study of Sun deep Cumber and colleagues, professional websites and health portals in diabetes have substantially improved on most criteria. Google and MedlinePlus have significantly outperformed other search engines in some standard metrics. Health care professionals manage diabetes, and existing systems now allow patients to self-report their blood glucose data and share with their health care provider [66]. Previous studies have identified the effectiveness of online blood glucose monitoring systems $[\underline{26}, \underline{67}]$.

In a study by Hugh D. Tildesley and colleagues from 409 patients, 388 patients with HbA1c were measured at baseline and after $\mathrm{HbA1c}$ reassessment after 9 months. HbA1c values ranged from 3 to 9 months on average for the production of follow-up data. Internet intervention has been effective in all groups, including type 1 diabetic patients [68]. Previously, there was a shortage of data to illustrate the effectiveness of online interventions in type 1 diabetic patients, and most studies have been conducted on much smaller amounts [69].

People rarely use the top 10 websites offered by Google and other search engines by default. On the other hand, there is evidence that the use of the Internet can improve the participation of patients in medical decision-making. In the study of chum ber et al. However, there is concern that patients may be misled by non-evidence-based methods or webbased treatments. Websites are potentially encouraging and replacing medical counseling [6]. It is often thought that the amount of information on the Internet is false and patients who cannot be trained in medicine cannot identify the wrong information $[\underline{70}, \underline{71}]$. In Table 3 presents the problem of intervention and the optimization method on the Internet.

Internet intervention has been effective in all groups, including type 1 diabetic patients. HbA1c reduces long-term diabetes and reduces costs. The effectiveness of this intervention is subject to the coverage of Internet services with insurance plans [69]. The only combination of both self-regulatory and frequent communication with the healthcare provider in reducing hemoglobin $\mathrm{A} 1 \mathrm{C}$ in patients with type 2 diabetes may only affect oral medications. Monitoring self-care in patients leads to recovery $[\underline{72}, \underline{73}]$.

In a study by Charlotte Vissenberg and colleagues of social networking interventions in self-management behaviors among type 2 diabetic patients living in deprived social and economic districts of Amsterdam in the Netherlands, a quasiexperimental study uses a hybrid approach. . From 131 people with social and economic deprivation with glycemic control, 69 subjects were assigned to the intervention group and 62 were assigned to the control group (standard diabetes education). 27 qualitative interviews with participants and 24 individuals from each group were used to examine the mental impact of interference. Additionally, autonomy behaviors (adherence to medication, diet, and physical activity) were evaluated at baseline, 10 and 16 months. The data were analyzed using framework analysis and linear mixing model. Qualitative results showed that the intervention group had a better understanding of how self-care management affects diabetes. The intervention group has more complicated self-care behaviors such as planning ahead, searching for appropriate foods and substitutes for physical activity, and considered permanent importance for diabetes. In participants with complete follow-up information, there was a significant increase in physical activity in the intervention group (4.83 days versus 3.78 ), and no changes were observed in the observance of the drug and diet [ㅍ].

Table 3: The problem of intervention and the optimization method on the Internet

\begin{tabular}{|c|c|c|c|}
\hline 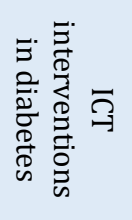 & 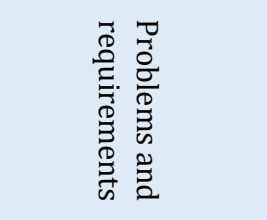 & 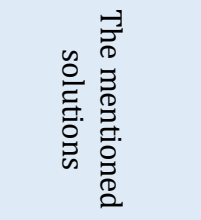 & 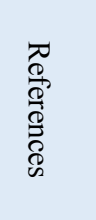 \\
\hline E-mail & $\begin{array}{l}\text { Lack of concurrent } \\
\text { interaction, the } \\
\text { existence of some } \\
\text { false information, } \\
\text { lack of } \\
\text { understanding and } \\
\text { understanding of } \\
\text { the information }\end{array}$ & $\begin{array}{l}\text { With image } \\
\text { or sound } \\
\text { support. } \\
\text { Ability to } \\
\text { exchange } \\
\text { information } \\
\text { bilaterally } \\
\text { (provider and } \\
\text { users) }\end{array}$ & $\frac{65}{70}-\underline{68}$ \\
\hline $\begin{array}{l}\text { social } \\
\text { network }\end{array}$ & $\begin{array}{l}\text { Lack of proper } \\
\text { understanding, } \\
\text { lack of } \\
\text { confidentiality, } \\
\text { lack of information }\end{array}$ & $\begin{array}{l}\text { Improved } \\
\text { security } \\
\text { through } \\
\text { training and } \\
\text { access } \\
\text { control }\end{array}$ & $\begin{array}{l}20 \\
\underline{74}-78\end{array}$ \\
\hline \multirow[t]{3}{*}{$\begin{array}{l}\text { Learn } \\
\text { from the } \\
\text { web }\end{array}$} & $\begin{array}{l}\text { 1) Internet } \\
\text { connection } \\
\text { problem, lack of } \\
\text { high quality and } \\
\text { fast computers }\end{array}$ & $\begin{array}{l}\text { Funding from } \\
\text { private and } \\
\text { public sectors }\end{array}$ & $\begin{array}{l}\frac{68}{69}, \\
\frac{76}{7}-78\end{array}$ \\
\hline & \multirow{2}{*}{$\begin{array}{l}\text { 2) Lack of } \\
\text { organized support } \\
\text { (webmaster, } \\
\text { developer, author } \\
\text { of content, quality } \\
\text { review, web } \\
\text { designer) }\end{array}$} & $\begin{array}{l}\text { Provide free } \\
\text { Wi-Fi }\end{array}$ & $\begin{array}{l}\underline{68}, \\
\underline{69}, 78\end{array}$ \\
\hline & & $\begin{array}{l}\text { Provide } \\
\text { training }\end{array}$ & $\begin{array}{l}\frac{65}{68}, \\
\underline{69}, 78\end{array}$ \\
\hline
\end{tabular}

In the study, Gabriela Spencer-Bonilla et al. identified various mechanisms through which social networks can affect diabetes self-care: 
1. sharing knowledge and

2. Facilitating access to resources, but only to the extent that patients can

3. Communicate with members of the network [75].

The logical model for self-management of social networks showed in Fig 4. Therefore, social networks may reduce (or exacerbate) and ineffective patients, and should take care of diabetes and follow the programs in line with the instructions and programs. However, social networks are usually designed in the design and evaluating interventions in chronic disease management; self-care programs are usually based on theories of changing individual behavior. The impact of socially-based interventions and the goal of supporting social networks on care and outcomes in patients with type 2 diabetes are still unclear $[\underline{76}, \underline{77}]$.

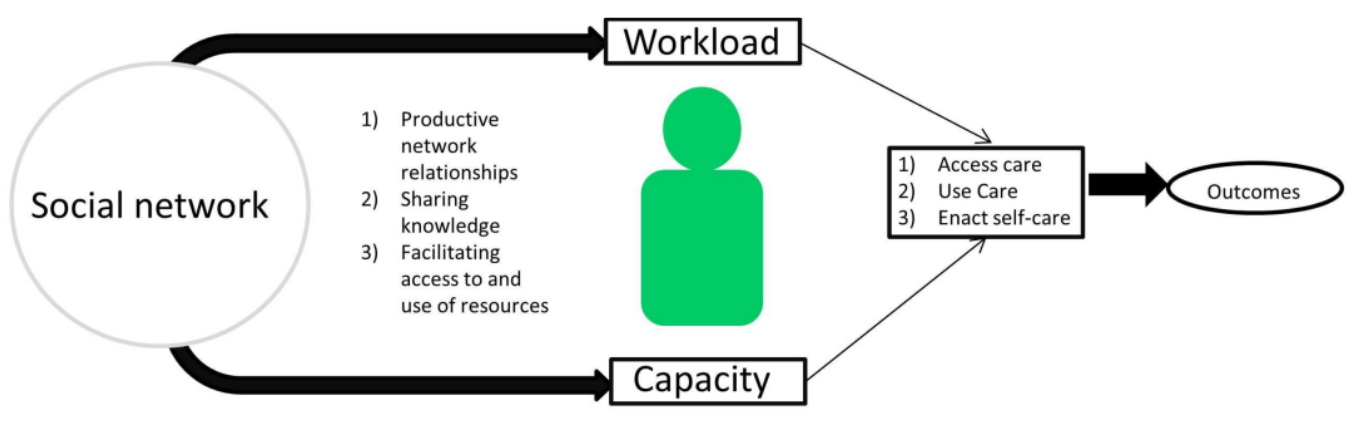

Fig 4: Logical model for self-management of social networks

Patients are very keen on interacting with the nurse over the Internet about their health issues and receiving clinical information through interactive charts. The feedback provided by nurses seems to increase the motivation of patients in diabetic selfmanagement. In general, the study shows that in most studies, internet intervention has been used primarily to transfer blood glucose data and other patient information to physicians and to use feedback on their health status. Subconsciously, this does not seem to be comprehensive and complete in the results of self-care in diabetes [으].

In the study, due to the increasing prevalence of diabetes and the high probability that patients with diabetes are searching on the Internet, the quality of the information is important. In fact, among the chronic conditions, patients with diabetes are likely to use the Internet $[\underline{79}, \underline{80}]$.

In general, surveys show that in most studies, internet intervention has been mainly used to transfer blood glucose data and other patient information to physicians and to use feedback on their health status $[\underline{81}, \underline{82}]$. Web-based learning is a tool for continuing education to increase the number and skills of health workers and patients. This learning method is possible for decentralized education without geographical and financial barriers. The potential limitations of equipment and broadband dependency, as well as the limitation for specialist training, require the interaction of face to face [요].

\section{DISCUSSION}

Considering the need to pay attention to diabetes and managing them in the technological age of today, the current review was conducted. By examining all interventions in the field of information technology in diabetes, all interventions related to new technologies in diabetes management were categorized into three categories of intervention including: 1) mobile and 2) telemedicine and tele-monitoring 3) Internet.

In the study of Lyles CR et al., The mobile healthcare tool (M-health) and Health Information Technology (HIT) are rapidly increasing to increase diabetes health and health management, including websites, mobile applications, messages Text or telephone contacts, remote monitoring devices / sensors and personal health records (PHRs) related to electronic health records $[\underline{21}, \underline{84}]$. Many systematic studies and studies have shown that the additional communication and support provided by such technologies can improve outcomes such as patient self-esteem, self-care, quality of life, and even health outcomes such as glycemic control. However, new evidence suggests that digital divide is less common in the use of widespread health technologies disseminated among racial/minority groups or those with limited health literacy [여-86].

1. Diabetes programs need to boost more features that improve diabetes.

2. M-Health health programs should provide a diverse range of types of health information, especially for laboratory tests, and healthcare providers. 
3. Health care providers should review the features and types of health information provided in the program so that they can recommend appropriate programs for patients [ㄱ]

A program for healthcare professionals with remote monitoring improves the quality of life of patients with a disease or clinical condition. There are signs that intervention has a different effect on patients with diabetes. Diabetic patients may, at the time of the intervention, initiate new ways to autonomously manage their chronic illnesses, which should not be ignored [49].

Although the ownership and use of devices among racial/ethnic minorities, low-income people and other sub-groups is also increasing [08-90]. In general, access, skills and barriers to productivity and use of this gap Digital ultimate affect [91]. There is strong evidence that good self-care and good care in chronic diabetes leads to better therapeutic outcomes $[\underline{19}, \underline{92}, \underline{93}]$.

Social media can be effective in promoting health through social media, like encouraging healthy behaviors through messages in social groups. The web has opened up access to information and interaction between individuals with similar or different ideas. In rural areas with Internet access, such networks may be an efficient channel for public information campaigns or preventive messages about stopping smoking, choosing a diet, and preventing injuries. An initiative that can help to use from social networks for diabetes, creating information web pages about the disease is designed within social science networks. Or social networks specifically for people with diabetes [ㅁ] $]$.

In a study by Charlotte Vissenberg et al., A collaborative support group is required to intervene simultaneously to improve self-care behaviors among disadvantaged people and states that further studies are necessary to justify the further implementation of intervention [74].

Health educators and patients using tele-monitoring have been able to see patient measurements in PHR and it is recommended that patients establish telephone calls with health educators during the program. In addition, a self-care guide has been given to patients in order to increase knowledge and knowledge about their chronic illness [49].

To further support patients in their efforts to better control diabetes, recent studies have tried to examine the use and effectiveness of technologies such as the Internet and mobile phones to facilitate and support the self-efficacy of diabetic patients, in addition, some interventions, resources Extras such as dedicated health care personnel are required to operate a personal messaging system or tools for the use of people who may not be readily available outside the study [오 $\underline{40}, \underline{94}]$. The findings are consistent with the research and show that most interventions and techniques are needed to maintain the behavior over time $[64, \underline{95}]$. Studies in motivational interviewing show flexibility as an important factor in intervention, because one or more behavioral techniques can be adopted in any diabetic person, while ensuring that the principle of mentality and personality-centered in motivational interviewing and treatment to be preserved $[\underline{30}, \underline{92}]$. Research in the field of diabetic foot ulcer prevention training focuses on knowledge, skills, and intensive care [의-98]. World Health Organization reports that studies that improve adherence to them will save costs and increase the effectiveness of health interventions [19, $\underline{99}]$. Motivation is recognized as a key factor in changing behavior and adherence [100-102]. There is sufficient evidence that motivational interviewing or behavioral interventions are consistent with increasing self-esteem in preventing diabetic foot ulcers. Interactive motivational interviews with effective interventions of positive behavioral change and adherence to treatment in news studies [103105]. In a study by Cheick Oumar Bagayoko et al., The use of information and communication technology (ICT) has struggled against diabetes, especially in recent years. The extent to which these technologies can be effective in the prevention and treatment of diabetes is somewhat illustrated. ICT interventions that can significantly improve one or more diabetes indices. The studies that have been conducted aimed at assessing the impact of information and communication technology on diabetes indices include all types of ICT applications: cell phone health, telephone counseling, telephony expertise, electronic health records, support systems Decision, e-learning and ... The results of the study are of interest to diabetes clinical indicators that can report the impact of ICT interventions [106]. These are the main and measurable indicators of diabetes monitoring and management that are commonly accepted by diabetes experts. And such research can identify the most effective ICT interventions to improve Diabetes mellitus help [106].

\section{CONCLUSION}

This study is an overview of ICT in diabetes control, which will provide valuable results for patients, service providers and researchers. It is recommended that the effectiveness of self-care systems be evaluated extensively, as well as aspects of self-management, long-term follow-up, cost factor, technology acceptance, satisfaction, and evaluation. The results of this study can help researchers measure the effectiveness of information and communication technology in diabetes self-care and therapeutic systems in different areas, and motivation should be considered as a key factor in behavioral change and adherence, 
and the sustainability of interventions and compliance. It should be observed in the patient by maintaining the behavior over time. Therefore, there is a fundamental need for more comprehensive interventions in which several technologies for managing chronic conditions, such as diabetic patients, are integrated, and IT interventions should be technically established and designed and implemented in user-based and social design principles. And technical attention was paid to minimizing the percentage of errors and abnormalities, resulting in better therapeutic outcomes of the disease, thereby reducing costs and increasing effectiveness.

\section{AUTHOR'S CONTRIBUTION}

All the authors approved the final version of the manuscript.

\section{CONFLICTS OF INTEREST}

The authors declare no conflicts of interest regarding the publication of this study.

\section{FINANCIAL DISCLOSURE}

No financial interests related to the material of this manuscript have been declared.

\section{REFERENCES}

1. World Health Organization. World health statistics 2016: Monitoring health for the SDGs sustainable development goals. World Health Organization; 2016.

2. Center for Disease Control and Prevention. National Diabetes Month-November 2017. MMWR Morb Mortal Wkly Rep 2017;66:1165.

3. Guariguata L, Whiting DR, Hambleton I, Beagley J, Linnenkamp U, Shaw JE. Global estimates of diabetes prevalence for 2013 and projections for 2035. Diabetes Res Clin Prac. 2014; 103(2): 137-49. PMID: 24630390 DOI: $\quad 10.1016 /$ j.diabres.2013.11.002 [PubMed]

4. Sedehi M, Mehrabi Y, Kazemnejad A, Hadaegh F. Comparison of artificial neural network, logistic regression and discriminant analysis methods in prediction of metabolic syndrome. Iranian Journal of Endocrinology and Metabolism. 2009; 11(6): 638-46.

5. Brasil CCP, Carlos DdAO, Vasconcelos Filho JE. Vocal health and mHealth: novel alternatives for old scenarios. Revista Brasileira em Promoção da Saúde. 2017; 30(1): 3-4.

6. Tapak L, Mahjub H, Hamidi O, Poorolajal J. Real-data comparison of data mining methods in prediction of diabetes in Iran. Healthc Inform Res. 2013; 19(3): 177-85. PMID: 24175116 DOI: 10.4258/hir.2013.19.3.177 [PubMed]

7. Richardson MJ, Van Den Eeden SK, Roberts E, Ferrara A, Paulukonis S, English P. Evaluating the Use of
Electronic Health Records for Type 2 Diabetes Surveillance in 2 California Counties, 2010-2014. Public Health Rep. 2017; 132(4): 463-70. PMID: $28586621 \quad$ DOI: $10.1177 / 0033354917708988$ [PubMed]

8. Ameri H, Alizadeh S, Akhond Zadeh Noughabi E. Application of data mining techniques in clinical decision making: A literature review and classification. In: Akhond Zadeh Noughabi E, Raahemi B, Albadvi A, Far BH. Handbook of research on data science for effective healthcare practice and administration. IGI Global; 2017. pp. 257-95.

9. Whiting DR, Guariguata L, Weil C, Shaw J. IDF diabetes atlas: global estimates of the prevalence of diabetes for 2011 and 2030. Diabetes Res Clin Prac. 2011; 94(3): 311-21. PMID: 22079683 DOI: 10.1016/j.diabres.2011.10.029 [PubMed]

10. Déglise C, Suggs LS, Odermatt P. SMS for disease control in developing countries: a systematic review of mobile health applications. J Telemed Telecare. 2012; 18(5): 273-81. PMID: 22826375 DOI: 10.1258/jtt.2012.110810 [PubMed]

11. West D. How mobile devices are transforming healthcare. Issues in Technology Innovation. 2012; 18(1): 1-11.

12. Nazari E, Nazari S. Selfcare in type I diabetes with continuous glucose monitoring. Front Health Inform. 2019; 8(1): e5.

13. Ershad Sarabi R, Sadoughi F, Jamshidi Orak R, Bahaadinbeigy K. The effectiveness of mobile phone text messaging in improving medication adherence for patients with chronic diseases: A systematic review. Iran Red Crescent Med J. 2016; 18(5): e25183. PMID: 27437126 DOI: 10.5812/ircmj.25183 [PubMed]

14. Zolfaghari M, Mousavifar SA, Pedram S, Haghani H. The impact of nurse short message services and telephone follow-ups on diabetic adherence: which one is more effective? J Clin Nurs. 2012; 21(13-14): 1922-31. PMID: 22239205 DOI: 10.1111/j.13652702.2011.03951.x [PubMed]

15. Sarkar S, Sivashankar P, Seshadri H. Mobile SMS reminders for increasing medication adherence. Int J Pharm Sci Rev Res. 2015; 32(1): 228-37.

16. Iman M, Saadabadi A, Davood A. Docking studies of phthalimide pharmacophore as a sodium channel blocker. Iran J Basic Med Sci. 2013; 16(9): 1016-21. PMID: 24171082 [PubMed]

17. Green LW, Brancati FL, Albright A, Primary Prevention of Diabetes Working Group. Primary prevention of type 2 diabetes: Integrative public health and primary care opportunities, challenges and strategies. Fam Pract. 2012; 29(suppl 1): i13-23.

18. Nazari E, Nazari S. Selfcare in type I diabetes with continuous glucose monitoring. Iran J Med Inform. 2019; 8(1): e5.

19. Hamine S, Gerth-Guyette E, Faulx D, Green BB, Ginsburg AS. Impact of $\mathrm{m}$-health chronic disease management on treatment adherence and patient outcomes: A systematic review. J Med Internet Res. 
2015; 17(2): e52. PMID: 25803266 DOI: 10.2196/jmir.3951 [․ubMed]

20. Henriquez-Camacho C, Losa J, Miranda JJ, Cheyne NE. Addressing healthy aging populations in developing countries: unlocking the opportunity of eHealth and m-health. Emerg Themes Epidemiol. 2014; 11(1): 136-44. PMID: 25642276 DOI: 10.1186/s12982-0140021-4 [PubMed]

21. Lyles CR, Ratanawongsa N, Bolen SD, Samal L. Mhealth and health information technology tools for diverse patients with diabetes. J Diabetes Res. 2017; 2017: 1-3. PMID: 28326330 DOI: 10.1155/2017/1704917 [PubMed]

22. Lyles CR, Sarkar U, Osborn CY. Getting a technologybased diabetes intervention ready for prime time: A review of usability testing studies. Cur Diab Rep. 2014; 14(10): 534-56. PMID: 25173689 DOI: 10.1007/s11892-014-0534-9 [PubMed]

23. Zhang X, Low S, Kumari N, Wang J, Ang K, Yeo D, et al. Direct medical cost associated with diabetic retinopathy severity in type 2 diabetes in Singapore. PloS One. 2017; 12(7): e0180949. PMID: 28700742 DOI: 10.1371/journal.pone.0180949 [PubMed]

24. Al-Taee MA, Al-Nuaimy W, Al-Ataby A, Muhsin ZJ, Abood SN. Mobile health platform fordiabetes management based on the Internet-of-Things. 2015 IEEE Jordan Conference on Applied Electrical Engineering and Computing Technologies (AEECT); 2015.

25. Goh G, Tan NC, Malhotra R, Padmanabhan U, Barbier $\mathrm{S}$, Allen JC, Jr., et al. Short-term trajectories of use of a caloric-monitoring mobile phone app among patients with type 2 diabetes mellitus in a primary care setting. J Med Internet Res. 2015; 17(2): e33. PMID: 25648130 DOI: 10.2196/jmir.3938 [PubMed]

26. Rodbard D. Continuous glucose monitoring: A review of recent studies demonstrating improved glycemic outcomes. Diabetes Technol Ther. 2017; 19(S3): S25S37. PMID: 28585879 DOI: 10.1089/dia.2017.0035 [PubMed]

27. Izahar S, Lean QY, Hameed MA, Murugiah MK, Patel RP, Al-Worafi YM, et al. Content analysis of mobile health applications on diabetes mellitus. Front Endocrinol. 2017; 8: 318-26. PMID: 29230195 DOI: 10.3389/fendo.2017.00318 [PubMed]

28. Ho EY, Chesla CA, Chun KM. Health communication with Chinese Americans about type 2 diabetes. Diabetes Educ. 2012; 38(1): 67-76. PMID: 22127677 DOI: $10.1177 / 0145721711428774$ [PubMed]

29. American Association of Cardiovascular and Pulmonary Rehabilitation. Guidelines for Cardiac Rehabilitation and Secondary Prevention Programs. Human Kinetics; 2013.

30. Powers MA, Bardsley J, Cypress M, Duker P, Funnell $\mathrm{MM}$, Fischl AH, et al. Diabetes self-management education and support in type 2 diabetes: a joint position statement of the American Diabetes Association, the American Association of Diabetes Educators, and the Academy of Nutrition and Dietetics. Clin Diabetes. 2016; 34(2): 70-80. PMID:

\section{DOI: 10.2337/diaclin.34.2.70 [PubMed]}

31. Smailhodzic E, Hooijsma W, Boonstra A, Langley DJ. Social media use in healthcare: A systematic review of effects on patients and on their relationship with healthcare professionals. BMC Health Serv Res. 2016; 16: 442-56. PMID: 27562728 DOI: 10.1186/s12913016-1691-0 [PubMed]

32. Gale R, Scanlon PH, Evans M, Ghanchi F, Yang Y, Silvestri G, et al. Action on diabetic macular oedema: Achieving optimal patient management in treating visual impairment due to diabetic eye disease. Eye (Lond). 2017; 31(S1): S1-S20. PMID: 28490797 DOI: 10.1038/eye.2017.53 [ PubMed]

33. Kelley JM, Kraft-Todd G, Schapira L, Kossowsky J, Riess H. The influence of the patient-clinician relationship on healthcare outcomes: A systematic review and meta-analysis of randomized controlled trials. PloS One. 2014; 9(4): e94207. PMID: 24718585 DOI: $10.1371 /$ journal.pone.0094207 [PubMed]

34. Wu S, Ell K, Jin H, Vidyanti I, Chou CP, Lee PJ, et al. Comparative effectiveness of a technology-facilitated depression care management model in safety-net primary care patients with type 2 diabetes: 6-month outcomes of a large clinical trial. J Med Internet Res. 2018; 20(4): e147. PMID: 29685872 DOI: 10.2196/jmir.7692 [PubMed]

35. Acharya B, Maru D, Schwarz R, Citrin D, Tenpa J, Hirachan S, et al. Partnerships in mental healthcare service delivery in low-resource settings: developing an innovative network in rural Nepal. Globalization and Health. 2017; 13(1): 1-7.

36. Young-Hyman D, De Groot M, Hill-Briggs F, Gonzalez JS, Hood K, Peyrot M. Psychosocial care for people with diabetes: A position statement of the American Diabetes Association. Diabetes care. 2016; 39(12): 2126-40. PMID: 27879358 DOI: 10.2337/dc16-2053 [PubMed]

37. Desveaux L, Shaw J, Saragosa M, Soobiah C, Marani H, Hensel J, et al. A mobile app to improve selfmanagement of individuals with type 2 diabetes: Qualitative realist evaluation. J Med Internet Res. 2018; 20(3): e81. PMID: 29549070 DOI: 10.2196/jmir.8712 [PubMed]

38. Patel V, Buchanan H, Hui M, Patel P, Gupta P, Kinder A, et al. How do specialist trainee doctors acquire skills to practice patient-centred care? A qualitative exploration. BMJ Open. 2018; 8(10): e022054.

39. Garabedian LF, Ross-Degnan D, Wharam JF. Mobile phone and smartphone technologies for diabetes care and self-management. Curr Diab Rep. 2015; 15(12): 109-24. PMID: 26458380 DOI: 10.1007/s11892-015-0680-8 [PubMed]

40. Kitsiou S, Paré G, Jaana M, Gerber B. Effectiveness of m-health interventions for patients with diabetes: An overview of systematic reviews. PloS One. 2017; 12(3): e0173160. PMID: 28249025 DOI: 10.1371/journal.pone.0173160 [PubMed]

41. Lewis BA, Napolitano MA, Buman MP, Williams DM, Nigg CR. Future directions in physical activity 
intervention research: expanding our focus to sedentary behaviors, technology, and dissemination. J Behav Med. 2017; 40(1): 112-26. PMID: 27722907 DOI: $10.1007 / \mathrm{s} 10865-016-9797-8$ [PubMed]

42. Siminerio LM, Albright A, Fradkin J, Gallivan J, McDivitt J, Rodríguez B, et al. The national diabetes education program at 20 years: Lessons learned and plans for the future. Diabetes Care. 2018; 41(2): 20918. PMID: 29358463 DOI: $10.2337 / \mathrm{dc} 17-0976$ [PubMed]

43. Jeong JY, Jeon JH, Bae KH, Choi YK, Park KG, Kim JG, et al. Smart care based on telemonitoring and telemedicine for type 2 diabetes care: Multi-center randomized controlled trial. Telemed J E Health. 2018; 24(8): 604-13. PMID: 29341843 DOI: 10.1089/tmj.2017.0203 [PubMed]

44. Toy BC, Myung DJ, He L, Pan CK, Chang RT, Polkinhorne A, et al. Smartphone-based dilated fundus photography and near visual acuity testing as inexpensive screening tools to detect referral warranted diabetic eye disease. Retina. 2016; 36(5): 1000-8. $\quad$ PMID: 26807627 DOI: 10.1097/IAE.0000000000000955 [PubMed]

45. Mansberger SL, Sheppler C, Barker G, Gardiner SK, Demirel S, Wooten K, et al. Long-term comparative effectiveness of telemedicine in providing diabetic retinopathy screening examinations: A randomized clinical trial. JAMA Ophthalmology. 2015; 133(5): 518-25. PMID: 25741666 DOI: 10.1001/jamaophthalmol.2015.1 [PubMed]

46. Vinekar A, Gilbert C, Dogra M, Kurian M, Shainesh G, Shetty B, et al. The KIDROP model of combining strategies for providing retinopathy of prematurity screening in underserved areas in India using widefield imaging, tele-medicine, non-physician graders and smart phone reporting. Indian J Ophthalmol. 2014; 62(1): 41-9. PMID: 24492500 DOI: 10.4103/0301-4738.126178 [PubMed]

47. Ting DS, Cheung GC, Wong TY. Diabetic retinopathy: global prevalence, major risk factors, screening practicesand public health challenges: A review. Clin Exp Ophthalmol. 2016; 44(4): 260-77. PMID: 26716602 DOI: $10.1111 /$ ceo.12696 [PubMed]

48. Guttmann-Bauman I, Kono J, Lin AL, Ramsey KL, Boston BA. Use of telehealth videoconferencing in pediatric type 1 diabetes in oregon. Telemed J E Health. 2018; 24(1): 86-8. PMID: 28654350 DOI: 10.1089/tmj.2017.0072 [PubMed]

49. Karhula T, Vuorinen AL, Rääpysjärvi K, Pakanen M, Itkonen $\mathrm{P}$, Tepponen $\mathrm{M}$, et al. Telemonitoring and mobile phone-based health coaching among Finnish diabetic and heart disease patients: Randomized controlled trial. J Med Internet Res. 2015; 17(6): e153. PMID: 26084979 DOI: 10.2196/jmir.4059 [PubMed]

50. Serrano CI, Shah V, Abràmoff MD. Use of expectation disconfirmation theory to test patient satisfaction with asynchronous telemedicine for diabetic retinopathy detection. Int J Telemed Appl. 2018; 2018: 7015272. PMID: 30405712 DOI: $10.1155 / 2018 / 7015272$ [PubMed]
51. Rosland AM, Piette JD, Trivedi R, Kerr EA, Stoll S, Tremblay A, et al. Engaging family supporters of adult patients with diabetes to improve clinical and patient-centered outcomes: Study protocol for a randomized controlled trial. Trials. 2018; 19(1): 394410. PMID: 30041685 DOI: 10.1186/s13063-0182785-2 [PubMed]

52. Eszes DJ, Szabó DJ, Russell G, Kirby P, Paulik E, Nagymajtényi L, et al. Diabetic retinopathy screening using telemedicine tools: Pilot study in Hungary. Journal of Diabetes Research. 2016; 2016: 1-9.

53. Edmonds M, Lázaro-Martínez JL, Alfayate-García JM, Martini J, Petit JM, Rayman G, et al. Sucrose octasulfate dressing versus control dressing in patients with neuroischaemic diabetic foot ulcers (Explorer): an international, multicentre, doubleblind, randomised, controlled trial. Lancet Diabetes Endocrinol. 2018; 6(3): 186-96. PMID: 29275068 DOI: 10.1016/S2213-8587(17)30438-2 [ubMed]

54. Yan M, Or C. Factors in the 4-week acceptance of a computer-based, chronic disease self-monitoring system in patients with type 2 diabetes mellitus and/or hypertension. Telemed J E Health. 2018; 24(2): 121-29. PMID: 28737995 DOI: 10.1089/tmj.2017.0064 [PubMed]

55. Nguyen HV, Tan GS, Tapp RJ, Mital S, Ting DS, Wong HT, et al. Cost-effectiveness of a national telemedicine diabetic retinopathy screening program in Singapore. Ophthalmology. 2016;123(12):257180. $\quad$ PMID: 27726962 DOI: 10.1016/j.ophtha.2016.08.021 [ubMed]

56. Brady CJ, Villanti AC, Gupta OP, Graham MG, Sergott RC. Tele-ophthalmology screening for proliferative diabetic retinopathy in urban primary care offices: An economic analysis. Ophthalmic Surg Lasers Imaging Retina. 2014; 45(6): 556-61. PMID: 25423636 DOI: $10.3928 / 23258160-20141118-11$ [PubMed]

57. Scott RE, Mars M. Telehealth in the developing world: Current status and future prospects. Smart Homecare Technology and TeleHealth. 2015; 3: 2537.

58. Winters D, Casten R, Rovner B, Murchison A, Leiby BE, Haller JA, et al. Cost-effectiveness of behavior activation versus supportive therapy on adherence to eye exams in older African Americans with diabetes. Am J Med Qual. 2017; 32(6): 661-7. PMID: 27884979 DOI: $\quad 10.1177 / 1062860616680290$ [PubMed]

59. Pasquel FJ, Hendrick AM, Ryan M, Cason E, Ali MK, Narayan KV. Cost-effectiveness of different diabetic retinopathy screening modalities. J Diabetes Sci Technol. 2016; 10(2): 301-7. PMID: 26719134 DOI: $10.1177 / 1932296815624109$ [PubMed]

60. De La Torre-Díez I, López-Coronado M, Vaca C, Aguado JS, de Castro C. Cost-utility and costeffectiveness studies of telemedicine, electronic, and mobile health systems in the literature: A systematic review. Telemed J E Health. 2015; 21(2): 81-5. PMID: 25474190 DOI: 10.1089/tmj.2014.0053 [PubMed]

61. Rajalakshmi R, Arulmalar S, Usha M, Prathiba V, 
Kareemuddin KS, Anjana RM, et al. Validation of smartphone based retinal photography for diabetic retinopathy screening. PLoS One. 2015; 10(9): e0138285. PMID: 26401839 DOI: 10.1371/journal.pone.0138285 [PubMed]

62. Kirkizlar E, Serban N, Sisson JA, Swann JL, Barnes CS, Williams MD. Evaluation of telemedicine for screening of diabetic retinopathy in the veterans health administration. Ophthalmology. 2013; 120(12): 2604-10. PMID: 24084501 DOI: 10.1016/j.ophtha.2013.06.029 [PubMed]

63. Rachapelle S, Legood R, Alavi Y, Lindfield R, Sharma $\mathrm{T}$, Kuper $\mathrm{H}$, et al. The cost-utility of telemedicine to screen for diabetic retinopathy in India. Ophthalmology. 2013; 120(3): 566-73. PMID: 23211635 DOI: $10.1016 /$ j.ophtha.2012.09.002 [PubMed]

64. Waaijman R, Keukenkamp R, de Haart M, Polomski WP, Nollet F, Bus SA. Adherence to wearing prescription custom-made footwear in patients with diabetes at high risk for plantar foot ulceration. Diabetes Care. 2013; 36(6):1613-8. PMID: 23321218 DOI: $10.2337 / \mathrm{dc} 12-1330$ [PubMed]

65. Lee JY, Lee SWH. Telemedicine cost-effectiveness for diabetes management: A systematic review. Diabetes Technol Ther. 2018; 20(7): 492-500. PMID: 29812965 DOI: $10.1089 /$ dia.2018.0098 [PubMed]

66. Chumber S, Huber J, Ghezzi P. A methodology to analyze the quality of health information on the internet: The example of diabetic neuropathy. Diabetes Educ. 2015; 41(1): 95-105. PMID: $25480397 \quad$ DOI: $\quad 10.1177 / 0145721714560772$ [PubMed]

67. Hunt CW. Technology and diabetes self-management: an integrative review. World J Diabetes. 2015; 6(2): 225-33. PMID: $25789104 \quad$ DOI: 10.4239/wjd.v6.i2.225 [PubMed]

68. Tildesley HD, Conway ME, Ross SA, Lee AM, Chan JH, Mazanderani $A B$, et al. Review of the effect of internet therapeutic intervention in patients with type 1 and type 2 diabetes. Diabetes Care. 2014; 37(2): e31-2. PMID: 24459161 DOI: $10.2337 / d c 13-$ 1940 [PubMed]

69. Shen Y, Wang F, Zhang X, Zhu X, Sun Q, Fisher E, et al. Effectiveness of Internet-based interventions on glycemic control in patients with type 2 diabetes: Meta-analysis of randomized controlled trials. J Med Internet Res. 2018; 20(5): e172. PMID: 29735475 DOI: 10.2196/jmir.9133 [PubMed]

70. Silver MP. Patient perspectives on online health information and communication with doctors: a qualitative study of patients 50 years old and over. J Med Internet Res. 2015; 17(1): e19. PMID: 25586865 DOI: 10.2196/jmir.3588 [PubMed]

71. O’Mathúna DP. How Should Clinicians Engage With Online Health Information? AMA Journal of Ethics. 2018; 20(11): 1059-66.

72. Mishuris RG, Yoder J, Wilson D, Mann D. Integrating data from an online diabetes prevention program into an electronic health record and clinical workflow, a design phase usability study. BMC Med Inform Decis Mak. 2016; 16: 88-101.

73. Majidi S, Jolly MC, Alonso GT, Buckingham DA, Cabrera $\mathrm{AB}$, Clements $\mathrm{MA}$, et al. Incorporating depression screening into diabetes clinics across the T1DX learning collaborative. Diabetes. 2018; 67(Supplement 1): 1309-18.

74. Vissenberg C, Nierkens V, van Valkengoed I, Nijpels G, Uitewaal P, Middelkoop B, et al. The impact of a social network based intervention on selfmanagement behaviours among patients with type 2 diabetes living in socioeconomically deprived neighbourhoods: A mixed methods approach. Scand J Public Health. 2017; 45(6): 569-83. PMID: 28707567 DOI: $10.1177 / 1403494817701565$ [PubMed]

75. Spencer-Bonilla G, Ponce OJ, Rodriguez-Gutierrez R, Alvarez-Villalobos N, Erwin PJ, Larrea-Mantilla L, et al. A systematic review and meta-analysis of trials of social network interventions in type 2 diabetes. BMJ Open. 2017; 7(8): e016506.

76. Foss C, Knutsen I, Kennedy A, Todorova E, Wensing $\mathrm{M}$, Lionis $\mathrm{C}$, et al. Connectivity, contest and the ties of self-management support for type 2 diabetes: A meta-synthesis of qualitative literature. Health Soc Care Community. 2016; 24(6): 672-86. PMID: 26429546 DOI: 10.1111/hsc.12272 [PubMed]

77. Ong BN, Rogers A, Kennedy A, Bower P, Sanders T, Morden A, et al. Behaviour change and social blinkers? The role of sociology in trials of self-management behaviour in chronic conditions. Sociology of Health \& Illness. 2014; 36(2): 226-38.

78. Landau Z, Mazor-Aronovitch K, Boaz M, Blaychfeld-Magnazi M, Graph-Barel C, Levek-Motola $\mathrm{N}$, et al. The effectiveness of Internet-based blood glucose monitoring system on improving diabetes control in adolescents with type 1 diabetes. Pediatr Diabetes. 2012; 13(2): 203-7. PMID: 21848925 DOI: 10.1111/j.1399-5448.2011.00800.x [PubMed]

79. Paul CL, Carey ML, Sanson-Fisher RW, Houlcroft LE, Turon HE. The impact of web-based approaches on psychosocial health in chronic physical and mental health conditions. Health Educ Res. 2013; 28(3): 45071. PMID: 23660463 DOI: $10.1093 /$ her/cyt053 [PubMed]

80. Edwards L, Thomas C, Gregory A, Yardley L, O'Cathain A, Montgomery AA, et al. Are people with chronic diseases interested in using telehealth? A cross-sectional postal survey. J Med Internet Res. 2014; 16(5): e123. PMID: 24811914 DOI: 10.2196/jmir.3257 [PubMed]

81. Chaudhury A, Duvoor C, Reddy Dendi VS, Kraleti S, Chada A, Ravilla R, et al. Clinical review of antidiabetic drugs: Implications for type 2 diabetes mellitus management. Front Endocrinol (Lausanne). 2017; 8: 1-12. PMID: 28167928 DOI: 10.3389/fendo.2017.00006 [PubMed]

82. Kumah-Crystal Y, Mulvaney S. Utilization of blood glucose data in patient education. Curr Diab Rep. 2013; 13(6): 886-93. PMID: 24057927 DOI: $10.1007 / \mathrm{s} 11892-013-0428-2$ [PubMed] 
83. Mbuagbaw L, Van Der Kop ML, Lester RT, Thirumurthy H, Pop-Eleches C, Ye C, et al. Mobile phone text messages for improving adherence to antiretroviral therapy (ART): An individual patient datameta-analysis of randomised trials. BMJ Open. 2013; 3(5): e002954. PMID: 23793704 DOI: 10.1136/bmjopen-2013-002954 [PubMed]

84. Hall AK, Cole-Lewis H, Bernhardt JM. Mobile text messaging for health: A systematic review of reviews. Annu Rev Public Health. 2015 Mar 18;36:393-415. PMID: 25785892 DOI: 10.1146/annurev-publhealth031914-122855 [PubMed]

85. Isaacs T, Hunt D, Ward D, Rooshenas L, Edwards L. The inclusion of ethnic minority patients and the role of language in telehealth trials for type 2 diabetes: A systematic review. J Med Internet Res. 2016; 18(9): e256. PMID: 27670360 DOI: 10.2196/jmir.6374 [PubMed]

86. Osborn CY, Mayberry LS, Mulvaney SA, Hess R. Patient web portals to improve diabetes outcomes: A systematic review. Curr Diab Rep. 2010; 10(6): 42235. PMID: 20890688 DOI: 10.1007/s11892-0100151-1 [PubMed]

87. Whitehead L, Seaton P. The effectiveness of selfmanagement mobile phone and tablet apps in longterm condition management: A systematic review. J Med Internet Res. 2016; 18(5): e97. PMID: 27185295 DOI: $10.2196 /$ jmir.4883 [PubMed]

88. Zickuhr K, Smith A. Digital differences. Pew Research Center. 2012.

89. Haight M, Quan-Haase A, Corbett BA. Revisiting the digital divide in Canada: The impact of demographic factors on access to the internet, level of online activity, and social networking site usage. Journal of Information, Communication \& Society. 2014; 17(4): 503-19.

90. Smith A. Technology adoption by lower income populations. Pew Research Center. 2013.

91. Perrin A. Social media usage. Pew Research Center. 2015.

92. American Diabetes Association. Standards of medical care in diabetes - 2016 abridged for primary care providers. Clinical Diabetes. 2016; 34(1): 3-12.

93. Jeffcoate WJ, Vileikyte L, Boyko EJ, Armstrong DG, Boulton AJ. Current challenges and opportunities in the prevention and management of diabetic foot ulcers. Diabetes Care. 2018; 41(4): 645-52. PMID: 29559450 DOI: $10.2337 / \mathrm{dc} 17-1836$ [PubMed]

94. Hou C, Carter B, Hewitt J, Francisa T, Mayor S. Do mobile phone applications improve glycemic control (HbA1c) in the self-management of diabetes? A systematic review, meta-analysis, and GRADE of 14 randomized trials. Diabetes Care. 2016; 39(11): 2089-95. PMID: 27926892 DOI: 10.2337/dc16-0346 [PubMed]

95. Bus SA, Waaijman R, Arts M, De Haart M, BuschWestbroek T, Van Baal J, et al. Effect of custom-made footwear on foot ulcer recurrence in diabetes: A multicenter randomized controlled trial. Diabetes Care. 2013: 36(12): 4109-16. PMID: 24130357 DOI:

\subsection{7/dc13-0996 [PubMed]}

96. Steinsbekk A, Rygg L, Lisulo M, Rise MB, Fretheim A. Group based diabetes self-management education compared to routine treatment for people with type 2 diabetes mellitus. A systematic review with metaanalysis. BMC Health Serv Res. 2012; 12: 213-32. PMID: 22824531 DOI: 10.1186/1472-6963-12-213 [PubMed]

97. Aalaa M, Sanjari M, Shahbazi S, Shayeganmehr Z, Abooeirad M, Amini MR, et al. Diabetic foot workshop: Improving technical and educational skills for nurses. Med J Islam Repub Iran. 2017; 31: 1-

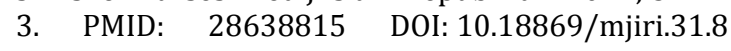
[PubMed]

98. Schaper N, Van Netten J, Apelqvist J, Lipsky B, Bakker $\mathrm{K}$, International Working Group on the Diabetic Foot. Prevention and management of foot problems in diabetes: A Summary Guidance for Daily Practice 2015, based on the IWGDF Guidance Documents. Diabetes Metab Res Rev. 2016; 32(Suppl 1): 7-15. PMID: 26335366 DOI: 10.1002/dmrr.2695 [PubMed]

99. Stanger C, Ryan SR, Delhey LM, Thrailkill K, Li Z, Li Z, et al. A multicomponent motivational intervention to improve adherence among adolescents with poorly controlled type 1 diabetes: A pilot study. J Pediatr Psychol. 2013; 38(6): 629-37. PMID: 23699750 DOI: 10.1093/jpepsy/jst032 [PubMed]

100. Walker KC, Valentiner LS, Langberg H. Motivational factors for initiating, implementing, and maintaining physical activity behavior following a rehabilitation program for patients with type 2 diabetes: A longitudinal, qualitative, interview study. Patient Prefer Adherence. 2018; 12: 145-52. PMID: 29403266 DOI: 10.2147/PPA.S150008 [PubMed]

101. Davis R, Campbell R, Hildon Z, Hobbs L, Michie S. Theories of behaviour and behaviour change across the social and behavioural sciences: A scoping review. Health Psychol Rev. 2015; 9(3): 323-44. PMID: 25104107 DOI: 10.1080/17437199.2014.941722 [PubMed]

102. Copeland L, McNamara R, Kelson M, Simpson S. Mechanisms of change within motivational interviewing in relation to health behaviors outcomes: A systematic review. Patient Educ Couns. 2015; 98(4): 401-11. PMID: 25535015 DOI: 10.1016/j.pec.2014.11.022 [ubMed]

103. Jansink R, Braspenning J, Keizer E, van der Weijden T, Elwyn G, Grol R. No identifiable Hb1Ac or lifestyle change after a comprehensive diabetes programme including motivational interviewing: A cluster randomised trial. Scand J Prim Health Care. 2013; 31(2): 119-27. PMID: 23659710 DOI: 10.3109/02813432.2013.797178 [ubMed]

104. Ulbrecht JS, Hurley T, Mauger DT, Cavanagh PR. Prevention of recurrent foot ulcers with plantar pressure-based in-shoe orthoses: The CareFUL prevention multicenter randomized controlled trial. Diabetes Care. 2014; 37(7): 1982-9. PMID: 24760263 DOI: $10.2337 / \mathrm{dc} 13-2956$ [ PubMed]

105.Lundahl B, Moleni T, Burke BL, Butters R, Tollefson $\mathrm{D}$, Butler $\mathrm{C}$, et al. Motivational interviewing in 
medical care settings : A systematic review and meta-analysis of randomized controlled trials. Patient Educ Couns. 2013; 93(2): 157-68. PMID: $24001658 \quad$ DOI: $10.1016 /$ j.pec.2013.07.012 [PubMed]

106. Bagayoko CO, Anne A, Gagnon M-P, Geissbuhler A. Effectiveness of ICT interventions for diabetes: A systematic overview (protocol). Journal of Health Informatics in Africa. 2018; 5(1): 1-7. 